Thorax, 1980, 35, 325-327

\title{
Cryoanalgesia in the management of pain after thoracotomy
}

\author{
C J GLYNN, J W LLOYD, AND J D W BARNARD \\ From the Pain Relief Unit, Abingdon Hospital, Abingdon, Oxfordshire
}

ABSTRACT The demand for postoperative analgesia was compared between 29 patients treated with cryoanalgesia to the relevant intercostal nerves during thoracotomy and a control group who did not have cryoanalgesia. The cryoanalgesia group required significantly less $(p<0.005)$ postoperative analgesia than did the control group.

Thoracotomy is generally considered to give rise to a painful surgical wound ${ }^{1}$ and in addition the procedure is associated with a high incidence of postoperative pulmonary complications. ${ }^{2}$ It has been suggested that there is a decrease in the incidence of pulmonary complications after extradural analgesia. ${ }^{3}$ Although an excellent method for achieving analgesia, thoracic extradural analgesia is a technique for the expert who has adequate nursing support and the correct environment. ${ }^{45}$ Alternative methods for relieving pain after thoracotomy include the use of narcotic analgesics and the block of relevant intercostal nerves with local analgesics. ${ }^{6}$ The longest acting agent commercially available is bupivacaine (Marcain) which has been reported to give analgesia for between nine and 18 hours. ${ }^{7}$ The injections may be performed by adequately trained junior medical staff, but there is a risk of creating a pneumothorax and the injections may have to be repeated several times.

The problem may be overcome by the use of cryoanalgesia which gives a median duration of pain relief of 26 days after treatment with the cryoprobe. ${ }^{8}$

In this study, 29 patients undergoing thoracic operations had a cryoprobe applied to the relevant intercostal nerves at the time of operation and the results were compared with a control group.

\section{Patients and methods}

The 29 patients in this study comprised 25 men and four women with a mean age of 60 years (range 19-75 yr). The diagnoses, confirmed at operation, were cancer of the lung (21), cancer of the stomach (three), spontaneous pneumothorax (two), lung abscess (two), hiatus hernia (one).

The operations performed were 17 right postero-

Address for reprint requests: Dr JW Lloyd, Pain Relief Unit, Abingdon Hospital, Abingdon, Oxfordshire. lateral thoracotomies, five left posterolateral thoracotomies, two right anterior thoracotomies, one left anterior thoracotomy, and four thoracolaparotomies, all by the same surgeon. Anaesthesia, administered under the direction of one of three different consultants, consisted of intermittent positive pressure ventilation (IPPV) with oxygen, nitrous oxide and muscle relaxant which was supplemented with halothane or fentanyl.

After completion of the operation and while the thorax was still open, a Spembly-Lloyd cryoprobe was applied under direct vision to each of the intercostal nerves to be frozen, as near to the intervertebral foramen as possible. A temperature of minus $60^{\circ} \mathrm{C}$ was applied for one minute to each nerve, which was then allowed to thaw: it was then refrozen to the same temperature for another minute. ${ }^{8}$ All the intercostal nerves from one above the upper limit of the incision to one below the lower limit of the incision or the chest drain, whichever was the lower, were treated in this way. ${ }^{9}$ The study was blind as far as the patients, nurses, and physiotherapists were concerned because cryoanalgesia was part of the operative procedure.

The 29 patients were matched for sex, age, and diagnosis with 29 other patients who had similar operations but who were prescribed postoperative analgesia alone and were not treated by cryoanalgesia. The 29 patients in the cryoanalgesia group were prescribed narcotic analgesics if required. In the cryoanalgesia group, one of us (CJG) tested sensation to pinprick over the anterior chest wall on the operative side within 48 hours of the operation in order to confirm the area of analgesia. In the postoperative period comparisons were made between these patients with regard to the amount and number of days of narcotic analgesia, the time to mobilisation and the time to discharge. 


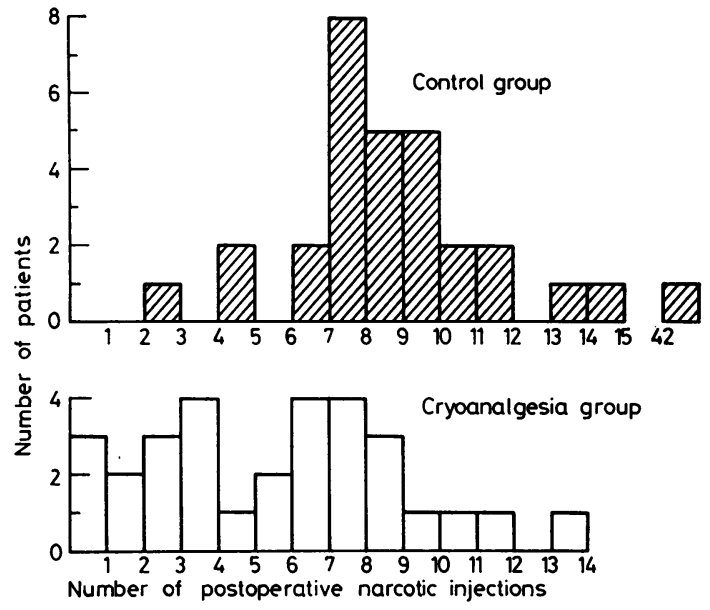

Figure Number of postoperative narcotic injections administered to both groups.

\section{Results}

The patients who received cryoanalgesia required significantly less narcotics $(p<0.005)$ after surgery than did those in the control group. However, there was no significant difference in the number of days for which narcotic analgesia was required between the two groups, (fig, table). When examined within 48 hours of operation, all the patients in the cryoanalgesia group had diminished sensation to pinprick in the distribution of the frozen nerves and none complained of pain in the wound. However these patients complained of pain outside the anaesthetic area. This was most commonly related to the drain wound but occasionally to the tip of the upper intrathoracic drain.

There was no significant difference between the two groups in relation to the time to mobilisation (one day) and the time to discharge (12-14 days).

\section{Discussion}

The results show that cryoanalgesia significantly reduced the number of narcotic injections required after thoracotomy. The fact that patients who

Table Number of postoperative narcotic injections given and number of days on which postoperative analgesia was required for the two groups studied expressed as a mean within the range

\begin{tabular}{|c|c|c|c|c|}
\hline \multirow[t]{2}{*}{ Group } & \multicolumn{2}{|c|}{$\begin{array}{l}\text { Number of postoperative } \\
\text { narcotic injections }\end{array}$} & \multicolumn{2}{|c|}{$\begin{array}{l}\text { Days of postoperative } \\
\text { narcotic injections }\end{array}$} \\
\hline & Mean & Range & $\overline{M e a n}$ & Range \\
\hline $\begin{array}{l}\text { Cryoanalgesia } \\
\text { Control }\end{array}$ & $\begin{array}{l}5 \\
9\end{array}$ & $\begin{array}{l}0-13 \\
2-42\end{array}$ & $\begin{array}{l}2 \cdot 6 \\
3 \cdot 1\end{array}$ & $\begin{array}{l}0-4 \\
2-7\end{array}$ \\
\hline
\end{tabular}

received cryoanalgesia required some further post- $\stackrel{\overrightarrow{\vec{D}}}{\overrightarrow{\vec{D}}}$ operative analgesia is not surprising because (a) there? was no pre-conditioning, ${ }^{210}$ and (b) 26 out of $29 \underline{\overline{\bar{c}}}$ patients complained of pain away from the thora- $\frac{\rho}{-}$ cotomy wound. It is interesting to note that only $\varnothing$ three patients in the control group received less than six postoperative injections compared with 15 in the $\rightarrow$ cryoanalgesia group (fig). All four patients who had. thoracolaparotomies in the cryoanalgesia group $\vec{\omega}$ required nine or more postoperative injections.

There is a suggestion that personality factors are $\vec{x}$ associated with complaints of pain in the post- $\omega_{\tilde{J}}$ operative period. However scores on the neuroticism ir dimension decrease with age and with male lung cancer. ${ }^{11}$ In this study the mean age of the groups $\mathrm{r}$ was 60 years and 20 of the 29 patients had cancer of을 the lung. Thus personality factors are unlikely to have affected the results significantly. Recent 3 information has suggested that the type of anaesthesia administered does not affect the demand $\overrightarrow{0}$ for postoperative analgesia. ${ }^{12}$

After thoracotomy, physiotherapy has an important role in the prevention of pulmonary compli-o cations. ${ }^{2}$ Although the physiotherapists on the ward were unaware of any study being performed, the increased cooperation of the patients who had received cryoanalgesia prompted them to ask if they had received anything in addition to the con-oํ글 ventional postoperative regime.

We would like to express our thanks to $\mathrm{Mr} \mathrm{AJ}^{-}$ Gunning for permission to study his patients and also to the physiotherapists on Ward VI at the Churchillo Hospital, Oxford.

\section{References}

1 Parkhouse J, Lambrechts W, Simpson BRJ. The incidence of postoperative pain. Br J Anaesth 1961 ? 33:345-53.

2 Abbey-Smith R. Pain relief after thoracotomy Lancet 1976; $1: 815-6$.

3 Simpson BRJ, Parkhouse J, Marshall R, Lambrechts ${ }^{\circ}$ W. Extradural analgesia and the prevention of postoperative respiratory complications. $\mathrm{Br}$ Anaesth 1961 ; 33:628-41.

4 Bromage PR. Extradural analgesia for pain relief. BrJ Anaesth 1967; 39:721-9.

5 Editorial. Pain relief after thoracotomy. Lancet 1976 1:576.

6 Loder RE. A long acting local anaesthetic solution for the relief of pain after thoracotomy. Thorax 1962을 17:375-6.

7 Moore DC. Intercostal nerve block for postoperativळ somatic pain following surgery of the thorax anf upper abdomen. Br J Anaesth 1975; 47:284-8.

8 Lloyd JW, Barnard JDW, Glynn CJ. Cryoanalgesiå a new approach to pain relief. Lancet $1976 ; 2: 932-4$. 
9 Foerster O. The dermatomes in man. Brain 1933; 56:1-39.

10 Roe RB. Are postoperative narcotics necessary? Arch Surg 1963; 87:912-5.

11 Boyle P, Parbrook GD. The interrelation of persona- lity and postoperative factors. $B r J$ Anaesth 1977; 49:259-64.

12 Henderson JJ, Parbrook GD. Influence of anaesthetic technique on postoperative pain. Br J Anaesth 1976; 48:587-91. 